\title{
Effect of capsinoids on energy metabolism in human subjects
}

\author{
Jose E. Galgani, Donna H. Ryan and Eric Ravussin* \\ Pennington Biomedical Research Center, 6400 Perkins Road, Baton Rouge, LA 70808, USA \\ (Received 18 February 2009 - Revised 11 June 2009 - Accepted 12 June 2009 - First published online 12 August 2009)
}

Capsinoids are non-pungent compounds with molecular structures similar to capsaicin, which has accepted thermogenic properties. To assess the acute effect of a plant-derived preparation of capsinoids on energy metabolism, we determined RMR and non-protein respiratory quotient (NPRQ) after ingestion of different doses of the capsinoids. Thirteen healthy subjects received four doses of the capsinoids (1, 3, 6 and $12 \mathrm{mg})$ and placebo using a crossover, randomised, double-blind trial. After a $10 \mathrm{~h}$ overnight fast as inpatients, RMR was measured by indirect calorimetry for 45 min before and $120 \mathrm{~min}$ after ingesting capsinoids or placebo. Blood pressure and axillary temperature were measured before $(-55$ and $-5 \mathrm{~min})$ and after (60 and $120 \mathrm{~min}$ ) dosing. Before dosing, mean RMR was 6247 (SE 92) kJ/d and NPRQ was 0.86 (SE 0.01). At 120 min after dosing, metabolic rate and NPRQ remained similar across the four capsinoids and placebo doses. Capsinoids also had no influence on blood pressure or axillary temperature. Capsinoids provided in four doses did not affect metabolic rate and fuel partitioning in human subjects when measured $2 \mathrm{~h}$ after exposure. Longer exposure and higher capsinoids doses may be required to cause meaningful acute effects on energy metabolism.

\section{Capsinoids: Thermogenesis: Respiratory quotient: Fat oxidation}

Obesity is pandemic and continues to increase in developed, developing and even some societal strata in emerging economies $^{(1)}$. At present, energy restriction and increased physical activity are advocated in most weight control programmes; however, sustained changes in diet and physical activity are difficult to achieve.

Growing interest exists to find natural substances or extracts that modify energy balance. Capsaicinoids (i.e. capsaicin) are naturally present in chilli pepper. Capsaicin increases the activity of the sympathetic nervous system $^{(2)}$, in parallel with increased cathecolamine secretion ${ }^{(3-5)}$, energy expenditure $^{(4,6)}$ and fat oxidation ${ }^{(4,7,8)}$. However, given its strong pungency, not all people feel comfortable consuming it. Capsaicin-like compounds such as capsinoids (i.e. capsiate, dihydrocapsiate and nordihydrocapsiate) are much less pungent $^{(9,10)}$ and have also been shown to increase the activity of the sympathetic nervous system ${ }^{(11)}$, adipose tissue uncoupling protein content ${ }^{(12)}$, energy expenditure and fat oxidation $^{(12)}$ in mice. In human subjects, Ohnuki et al. ${ }^{(13)}$ found increased body temperature and higher $\mathrm{V}_{\mathrm{O}_{2}}$ after ingestion of a single dose of capsinoids-rich peppers ( $\mathrm{CH}-19$ sweet; Capsicum annuum L.). Additionally, an increased $\mathrm{V}_{\mathrm{O}_{2}}$ (per $\mathrm{kg}$ of body weight) associated with a small reduction in body weight was observed in overweight individuals after ingesting $10 \mathrm{mg} / \mathrm{d}$ of encapsulated capsinoids for 4 weeks ${ }^{(14)}$. Very recently, Snitker et al. ${ }^{(15)}$ have reported that overweight individuals ingesting $6 \mathrm{mg} / \mathrm{d}$ of encapsulated capsinoids for 12 weeks had increased fat oxidation and reduced abdominal fat compared with placebo-treated subjects. Unfortunately, in these studies, energy expenditure was not normalised for the metabolically active mass, making the comparison within and between groups difficult with changes in body weight and body composition. Therefore, we investigated the acute effect of encapsulated capsinoids on metabolic rate and substrate oxidation in a crossover study.

We conducted a double-blind, placebo-controlled, single centre, randomised, crossover clinical trial to test the impact of different doses of encapsulated, plant-derived capsinoids (1, 3, 6 and $12 \mathrm{mg}$ ) on RMR and fat oxidation measured by indirect calorimetry. The primary objective of this randomised trial was to test the hypothesis that consumption of capsinoids increases resting energy expenditure and/or fat oxidation in human subjects. The secondary objective was to evaluate the effect of capsinoids on blood pressure and adverse events.

\section{Methods}

\section{Subjects}

Thirteen young (28.4 (SE 1.4) years), non-smoking men were recruited by advertising in local newspaper, television and the Pennington Biomedical Research Center website. They were healthy as indicated by physical examination and routine medical laboratory tests and their body weight was stable over the past month. Participants had an average BMI of $27 \cdot 1$ (SE 1.0$) \mathrm{kg} / \mathrm{m}^{2}$ ranging from 22.3 to 34.8 , body weight of 83.9 (SE 4.7$) \mathrm{kg}$ (range: $60.5-117.5$ ) and body fat content of 22.4 (SE 1.6) \% (range: 11.9-31.3). None of them exercised more than twice a week for the past 6 months and none participated in regular resistance exercise. Exclusion criteria 
also included attempt to diet to increase or decrease body weight, allergy to chilli pepper, consuming more than two cups of tea or coffee per day or more than three standard alcohol drinks per day, use of weight loss drugs, drugs affecting energy metabolism and drugs for depression. The protocol was approved by the Pennington Biomedical Research Center Institutional Review Board and all subjects provided written informed consent.

\section{Experimental design}

The present study was a double-blind, placebo-controlled, randomised, crossover clinical trial. After completing the screening process, participants presented at 18.00 hours at the Pennington inpatient unit for $5 \mathrm{~d}$. At 18.30 hours, they received a standardised dinner and, at 20.00 hours, a snack. This provided $50 \%$ of the basal energy requirement, calculated according to published equations ${ }^{(16)}$. The macronutrient composition of the diet was $50 \%$ from carbohydrates, $30 \%$ from fat and $20 \%$ from protein. At 21.00 hours, subjects were interviewed for the occurrence of symptoms within the last 12 hours $^{(17)}$. On the next day, in order to minimise physical activity, subjects remained in their bed for the entire duration of the RMR assessment. RMR was measured for $45 \mathrm{~min}$ (baseline) before ingestion of twelve gel capsules followed by another $120 \mathrm{~min}$ of RMR measurement. Doses (placebo or capsinoids at 1, 3,6 or $12 \mathrm{mg}$ ) were randomly assigned using a randomised number sequence. Urine was collected before and after the $165 \mathrm{~min}$ RMR measurement for nitrogen excretion rate. Blood pressure and body temperature were measured at $-50,-5,60$ and 120 min of capsules ingestion. At the end of the $165 \mathrm{~min}$ RMR measurement, occurrence of symptoms for the last $3 \mathrm{~h}$ was assessed according to a symptoms' checklist ${ }^{(17)}$. Total body fat content was measured by dual energy X-ray absorptiometry scan on one of the mornings after RMR testing. Finally, $72 \mathrm{~h}$ after the last testing day, subjects were contacted by phone and interviewed for the presence of symptoms and adverse events. Physical activity and consumption of tea, coffee and alcohol were not permitted during the week of metabolic evaluation.

\section{Capsinoids capsules}

Capsules contained an extract from pepper fruit variety $\mathrm{CH}-19$ sweet ( $C$. annuum L.). Capsinoids oil was extracted as follows: dried fruit was treated with hexane, and fruit sediment was removed by filtration, followed by evaporation and distillation with medium-chain TAG and column chromatography to yield purified capsinoids. Capsinoids consisted of capsiate, dihydrocapsiate and norhydrocapsiate in a 70:23:7 ratio (HPLC). The purified capsinoids were dissolved in rapeseed oil and encapsulated in vegetarian softgel capsules made of modified maizestarch, vegetable glycerine and carageenan; each capsule contained $1 \mathrm{mg}$ capsinoids and $199 \mathrm{mg}$ of a mixture of rapeseed oil and medium-chain TAG. All capsules were manufactured in one batch. Stability tests determined that the product would be stable beyond the duration of the trial. The same amount of capsules (twelve) was given every testing day, but with different proportions of capsules containing placebo or capsinoids. For example, with the $6 \mathrm{mg}$ capsinoids dose, six capsules contained placebo and six capsules contained capsinoids. Capsules were ingested with $150 \mathrm{ml}$ of tap water in less than $2 \mathrm{~min}$, and they are expected to be absorbed within $10 \mathrm{~min}$.

\section{Indirect calorimetry and fuel oxidation}

RMR was measured in fasting conditions with subject in supine position, awake, in a quiet environment (soft music was permitted) and with a room temperature of $22^{\circ} \mathrm{C}$. RMR was determined from gas exchange measurements using a Deltatrac II metabolic cart (Deltatrac II, Datex-Ohmeda, Helsinki, Finland). The analyser was calibrated before each study with standardised gases containing $5 \% \mathrm{CO}_{2}$ and $95 \%$ $\mathrm{O}_{2}$. A transparent plastic hood connected to the device was placed over the head of the participant. $\mathrm{V}_{\mathrm{O}_{2}}$ and $\mathrm{V}_{\mathrm{CO}_{2}}$ were calculated from continuous measurements of $\mathrm{CO}_{2}$ and $\mathrm{O}_{2}$ concentrations in inspired and expired air diluted in a constant air flow of approximately 40 litres $/ \mathrm{min}$. $\mathrm{V}_{\mathrm{O}_{2}}, \mathrm{CO}_{2}$ production and energy expenditure standardised for temperature, pressure and moisture were calculated at $1 \mathrm{~min}$ intervals. Energy substrate oxidation was calculated using Jequier et al. equations $^{(18)}$ taking into account urinary nitrogen excretion. The RMR response to the drug was evaluated as the net incremental area under the curve ${ }^{(19)}$.

\section{Body composition}

Body fat mass and fat-free mass were measured on a Hologic Dual Energy X-ray Absorptiometer in the fan beam mode (QDR 4500; Hologic, Waltham, MA, USA).

\section{Blood pressure and body temperature}

Blood pressure was measured at $-50,-5,0,60$ and $120 \mathrm{~min}$ of capsule ingestion using a manometer (Baumanometer; W.A. Baum Co., Inc., Copiague, NY, USA). Axillary body temperature was measured using an electronic thermometer (Sure Temp 679, Welch Allyn, Skaneateles Falls, NY, USA).

\section{Symptoms and adverse events}

Assessment of the incidence of symptoms and adverse events, which might possibly be induced by capsinoids, was done using a validated symptom questionnaire ${ }^{(17)}$. This questionnaire assesses thirty-four different symptoms (e.g. energetic, tired, hungry, fresh, alert, sleepy, etc.) in four different intensities: not at all; slight amount; moderate amount; great amount. The questionnaire was applied the night before the metabolic testing, immediately after the 165 min metabolic testing and $72 \mathrm{~h}$ after the last metabolic testing.

\section{Statistical analysis}

Data are expressed as mean \pm SE. All statistical analyses were done with SAS software version 9.1.3 (SAS Institute, Inc., Cary, NC, USA). Data were analysed using a two-way repeated-measures ANOVA (SAS PROC MIXED) with dose and time as the fixed effects and subject as the random effect. The statistical significance for multiple comparisons was adjusted with respect to the Tukey-Kramer method 
to control for type I error rate. $P<0.05$ was considered statistically significant.

The present study was conducted according to the guidelines laid down in the Declaration of Helsinki, and all procedures involving human subjects were approved by the Pennington Biomedical Research Center Institutional Review Board (\#27 034). Written informed consent was obtained from all subjects.

\section{Results}

All subjects completed the $5 \mathrm{~d}$ metabolic rate assessment. No significant changes in body weight were detected during this period $(0.15$ (SE 0.18$) \mathrm{kg}$; range: -1.1 to $1.3 ; P=0.41)$. Capsinoids' capsules were well tolerated and adverse events were similar across treatments $(P=0 \cdot 09)$. Likewise, systolic and diastolic blood pressures were unchanged over time and unaffected by capsinoids. A small but statistically significant increase in body temperature was observed when body temperature was compared at -50 and $120 \mathrm{~min}$ after ingestion of the capsules $\left(35.9(\operatorname{SE~} 0.1)\right.$ to $\left.36 \cdot 0(\operatorname{SE~} 0.0)^{\circ} \mathrm{C} ; P=0.02\right)$, but was not affected by treatment $(P=0 \cdot 16)$.

\section{Energy metabolism}

RMR before dosing had an intraindividual CV of $4.1 \%$ $(\mathrm{SD}=259 \mathrm{~kJ} / \mathrm{d})$. After capsinoids ingestion, no differences in metabolic rate were noted as a function of time $(P=1.00)$, capsinoids dose $(P=0.91)$ or its interaction $(P=1.00$; Fig. 1(A)). The RMR incremental area under the curve $(\mathrm{kJ} \mathrm{min} / \mathrm{d})$ was also similar between doses $(P=0.48$; Table 1$)$. In addition, the change in metabolic rate in response to dosing did not show differences when compared with placebo $(P>0.53$; Table 1$)$.

The intraindividual variability in non-protein respiratory quotient (NPRQ) before dosing was $3.1 \% \quad(\mathrm{SD}=0.03)$. NPRQ was not affected by treatment $(P=0 \cdot 36)$ or treatment $\times$ time interaction $(P=1 \cdot 00)$. However, a significant time effect was noted $(P=0.002$; Fig. $1(B))$ with a decrease in NPRQ 30 and $60 \mathrm{~min}$ after dosing. After that time, NPRQ values were similar to those observed during the baseline period $(P=0 \cdot 19$; Fig. 1(B)).

Fat oxidation before capsules ingestion had an intraindividual $\mathrm{CV}$ of $45 \%$ ( $\mathrm{SD}=18 \mathrm{~g} / \mathrm{d})$. No significant effect of capsinoids dose was observed on fat oxidation $(P=0 \cdot 24)$. However, fat oxidation was increased $30 \mathrm{~min}(P=0.0002)$ and $60 \mathrm{~min}$ $(P=0.007)$ after dosing, when compared with baseline fat oxidation (baseline, 30 and $60 \mathrm{~min}$ : 40 (SE 3), 62 (SE 4) and 57 (SE 3$) \mathrm{g} / \mathrm{d}$, respectively). Mirror image results were observed for carbohydrate oxidation, which was reduced $30 \mathrm{~min}$ after dosing, when compared with baseline values (118 (SE 9) v. $156(\mathrm{SE} 8) \mathrm{g} / \mathrm{d}$, respectively; $P=0.01)$.

We also evaluated the influence of the chronological order (days 1, 2, etc.) on energy metabolism, and no differences were detected among days on baseline RMR (days 1, 2, 3, 4 and 5 in kJ/d: 6166 (SE 166), 6247 (SE 211), 6190 (SE 222), 6260 (SE 199) and 6379 (SE 262), respectively; $P=0.96$ ) or NPRQ (days 1, 2, 3, 4 and 5: 0.85 (SE 0.01), 0.87 (SE 0.01), 0.86 (SE 0.01), 0.87 (SE 0.01) and 0.86 (SE 0.02), respectively; $P=0.59)$. Similar results were found when the $2 \mathrm{~h}$ post-pill RMR and NPRQ were assessed.

\section{Discussion}

Using a crossover design, we failed to demonstrate a significant effect of capsinoids on metabolic rate and fuel partitioning in human subjects. With our design, we did not have to normalise energy expenditure data for body composition, since each subject was his own control with probably no change in body composition over the $5 \mathrm{~d}$ of testing. In addition to these results, blood pressure and axillary temperature were not affected by capsinoids.

One potential target for obesity treatment and/or prevention is metabolic rate. It is proposed that even a small decrease in energy intake $(<200 \mathrm{~kJ} / \mathrm{d})$ may be able to prevent weight gain $^{(20)}$, although this concept has been vigorously challenged ${ }^{(21-23)}$. Similarly, one can make the case that a small but consistent increase in energy expenditure will help individuals to maintain body weight or even lose weight.
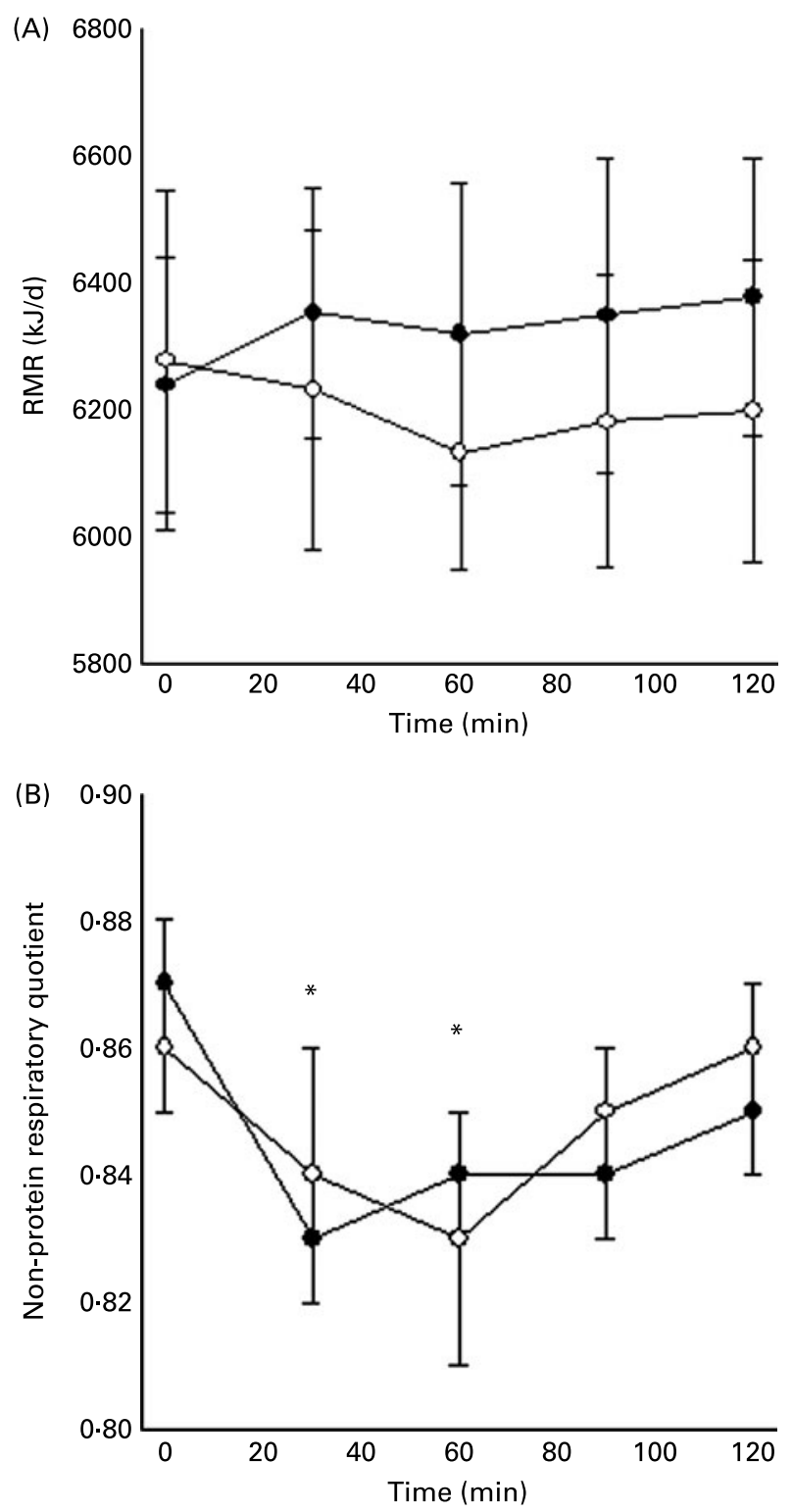

Fig. 1. RMR (A) and non-protein respiratory quotient $(B)$ before and for $120 \mathrm{~min}$ after $12 \mathrm{mg}$ capsinoids $(O)$ or placebo $(\bullet)$ ingestion. Data for lower doses (1, 3 and $6 \mathrm{mg}$ ) of capsinoids are not shown. ${ }^{\star} P<0.05$ compared with baseline. 
Table 1. RMR area under the curve and change from baseline to post-capsinoids ingestion* (Mean values with their standard errors)

\begin{tabular}{|c|c|c|c|c|c|c|c|c|c|c|c|}
\hline & \multicolumn{2}{|c|}{ Placebo } & \multicolumn{2}{|c|}{$1 \mathrm{mg}$} & \multicolumn{2}{|c|}{$3 \mathrm{mg}$} & \multicolumn{2}{|c|}{$6 \mathrm{mg}$} & \multicolumn{2}{|c|}{$12 \mathrm{mg}$} & \multirow{2}{*}{$\begin{array}{l}\text { Capsinoids effect } \\
\qquad(P \text { value })\end{array}$} \\
\hline & Mean & SE & Mean & SE & Mean & SE & Mean & SE & Mean & SE & \\
\hline RMR before pills ingestion (kJ/d) & 6238 & 201 & 6305 & 230 & 6180 & 163 & 6247 & 205 & 6276 & 268 & 0.99 \\
\hline RMR iAUC (kJ min/d) & 11163 & 8004 & -8435 & 11485 & 8435 & 9335 & -4134 & 8017 & -9858 & 13636 & 0.48 \\
\hline$\Delta \mathrm{RMR}_{\text {mean }}(\mathrm{kJ} / \mathrm{d})$ & 109 & 84 & -79 & 113 & 63 & 92 & -46 & 79 & -92 & 134 & 0.53 \\
\hline$\Delta \mathrm{RMR}_{\text {peak }}(\mathrm{kJ} / \mathrm{d})$ & 322 & 92 & 142 & 117 & 293 & 109 & 205 & 92 & 155 & 117 & 0.66 \\
\hline
\end{tabular}

RMR iAUC, RMR incremental area under the curve for 120 min after capsinoids or placebo ingestion; $\Delta$ RMR mean, mean RMR after capsinoids ingestion - baseline RMR; $\Delta \mathrm{RMR}_{\text {peak }}$, maximal RMR after capsinoids ingestion - baseline RMR.

* The mixed model with repeated measures was used with dose as the fixed effect and subject as the random effect.

The best option to increase energy expenditure is by increasing physical activity; however, the current obesogenic environment makes this option often difficult or impossible for most people ${ }^{(24)}$. Alternatively, ingestion of compounds with thermogenic properties in combination with energy restriction might eventually lead to higher body weight loss.

Capsinoids share a similar molecular structure with capsaicin. These compounds may therefore have a capsaicin-like effect on metabolic rate in human subjects since animal studies support such a thermogenic effect ${ }^{(11,12)}$. In human subjects, Inoue et al. ${ }^{(14)}$ assessed the effect of 3 and $10 \mathrm{mg} / \mathrm{d}$ of encapsulated capsinoids for 4 weeks on metabolic rate and respiratory quotient. No changes in these variables were observed. However, when only overweight individuals were included in the analysis, a larger increase in $\mathrm{V}_{\mathrm{O}_{2}}$ with the highest capsinoids dose $v$. placebo was detected. A similar but NS increase in metabolic rate and fat oxidation was observed $(P<0 \cdot 10)$, but without changes in respiratory quotient. Unfortunately, the lack of normalization of metabolic rate for the metabolically active body mass did not allow firm conclusions. In a recent study in overweight men, encapsulated capsinoids $(6 \mathrm{mg} / \mathrm{d}$ for 12 weeks) did not modify metabolic rate, although a higher but NS increase in fat oxidation was detected after the 12-week treatment period when compared with the placebo group. However, the authors failed to normalise their data for the metabolically active tissue before and after intervention ${ }^{(15)}$.

Several factors may explain the present results, including the low doses and short exposure to capsinoids, a lack of power to find significant differences or simply the absence of thermogenic effect of capsinoids. The present study was designed with the power to detect a $5 \%$ effect in RMR or approximately $300 \mathrm{~kJ} / \mathrm{d}$. After $2 \mathrm{~h}$ of metabolic rate measurement, the differences in RMR after capsinoids ingestion compared with placebo were well below our detection limit and more importantly of no physiological importance on body weight. Therefore, we are confident that the lack of significant difference is not due to a type II error.

Another possibility is that the measurement of energy expenditure was not of sufficient duration (only $120 \mathrm{~min}$ after dosing) to detect an effect. Such an observation has been made with sibutramine, a medication that is approved for obesity and which has a small effect on energy expenditure. Seagle et al. ${ }^{(25)}$ did not find an effect of sibutramine $(10 \mathrm{mg}$ or $30 \mathrm{mg} / \mathrm{d})$ in obese women when they measured RMR for only $3 \mathrm{~h}$. However, Hansen et al. ${ }^{(26)}$ measured energy expenditure for $5.5 \mathrm{~h}$ after dosing with $30 \mathrm{mg}$ sibutramine compared with placebo in fed and fasted men. There was a sibutramine-induced increase in energy expenditure of about $3-5 \%$. Data from mice also support the idea that longer exposure to high doses of capsinoids may be required to increase metabolic rate, since the thermogenic effect may be mediated by upregulation of uncoupling proteins ${ }^{(12)}$.

Alternatively, capsinoids might influence food intake by suppressing hunger and increasing satiety in human subjects ${ }^{(27-29)}$. We did not specifically assess food intake in the present study, although the symptoms' questionnaire given to the volunteers included a question about hunger feelings. We found no difference in hunger across treatments.

In conclusion, a combination of longer exposure time and higher capsinoids dose may be required to increase metabolic rate in a physiologically meaningful way. Therefore, there is still a need to investigate the potential long-term effects of capsinoids on metabolic rate in human subjects. In conclusion, the present study does not support the hypothesis that capsinoids can be helpful in increasing energy expenditure and fat oxidation in human subjects, at least over $2 \mathrm{~h}$ after exposure. Long-term use of capsinoids needs to be further tested to establish them as a potential weight control agent.

\section{Acknowledgements}

The present work was supported by Ajinomoto Co., Inc. (Tokyo, Japan) and partly by P30DK072476. J. E. G. was supported by a fellowship from The International Nutrition Foundation/Ellison Medical Foundation. Ajinomoto Co., Inc. did not have influence in the subjects' recruitment, data collection, analysis, interpretation and in the decision to publish the present study. E. R. did study design, data analysis and preparation of the manuscript. D. H. R. did study design and preparation of the manuscript. J. E. G. did data collection, analysis and preparation of the manuscript. Conflict of interest. None of the authors has any conflict of interest.

\section{References}

1. Nishida C, Uauy R, Kumanyika S, et al. (2004) The joint WHO/ FAO expert consultation on diet, nutrition and the prevention of chronic diseases: process, product and policy implications. Public Health Nutr 7, 245-250.

2. Watanabe T, Kawada T, Kurosawa M, et al. (1988) Adrenal sympathetic efferent nerve and catecholamine secretion 
excitation caused by capsaicin in rats. Am J Physiol 255 E23-E27.

3. Kawada T, Sakabe S, Watanabe T, et al. (1988) Some pungent principles of spices cause the adrenal medulla to secrete catecholamine in anesthetized rats. Proc Soc Exp Biol Med 188, 229-233.

4. Kawada T, Watanabe T, Takaishi T, et al. (1986) Capsaicininduced beta-adrenergic action on energy metabolism in rats: influence of capsaicin on oxygen consumption, the respiratory quotient, and substrate utilization. Proc Soc Exp Biol Med 183, 250-256.

5. Watanabe T, Kawada T, Yamamoto M, et al. (1987) Capsaicin, a pungent principle of hot red pepper, evokes catecholamine secretion from the adrenal medulla of anesthetized rats. Biochem Biophys Res Commun 142, 259-264.

6. Yoshioka M, Lim K, Kikuzato S, et al. (1995) Effects of red-pepper diet on the energy metabolism in men. J Nutr Sci Vitaminol (Tokyo) 41, 647-656.

7. Yoshioka M, St-Pierre S, Suzuki M, et al. (1998) Effects of red pepper added to high-fat and high-carbohydrate meals on energy metabolism and substrate utilization in Japanese women. $\mathrm{Br} J$ Nutr 80, 503-510.

8. Lejeune MP, Kovacs EM \& Westerterp-Plantenga MS (2003) Effect of capsaicin on substrate oxidation and weight maintenance after modest body-weight loss in human subjects. $\mathrm{Br} \mathrm{J}$ Nutr 90, 651-659.

9. Kobata K, Sutoh K, Todo T, et al. (1999) Nordihydrocapsiate, a new capsinoid from the fruits of a nonpungent pepper, Capsicum annuum. J Nat Prod 62, 335-336.

10. Iida T, Moriyama T, Kobata K, et al. (2003) TRPV1 activation and induction of nociceptive response by a non-pungent capsaicin-like compound, capsiate. Neuropharmacology 44, 958-967.

11. Ohnuki K, Haramizu S, Oki K, et al. (2001) Administration of capsiate, a non-pungent capsaicin analog, promotes energy metabolism and suppresses body fat accumulation in mice. Biosci Biotechnol Biochem 65, 2735-2740.

12. Masuda Y, Haramizu S, Oki K, et al. (2003) Upregulation of uncoupling proteins by oral administration of capsiate, a nonpungent capsaicin analog. J Appl Physiol 95, 2408-2415.

13. Ohnuki K, Niwa S, Maeda S, et al. (2001) CH-19 sweet, a non-pungent cultivar of red pepper, increased body temperature and oxygen consumption in humans. Biosci Biotechnol Biochem 65, 2033-2036.

14. Inoue N, Matsunaga Y, Satoh H, et al. (2007) Enhanced energy expenditure and fat oxidation in humans with high BMI scores by the ingestion of novel and non-pungent capsaicin analogues (capsinoids). Biosci Biotechnol Biochem 71, 380-389.
15. Snitker S, Fujishima Y, Shen H, et al. (2009) Effects of novel capsinoid treatment on fatness and energy metabolism in humans: possible pharmacogenetic implications. Am J Clin Nutr 89, 45-50.

16. Human energy requirements. Scientific background papers from the Joint FAO/WHO/UNU Expert Consultation (2005) October 17-24, 2001, Rome, Italy. Public Health Nutr 8, 929-1228.

17. Wadden TA, Stunkard AJ, Day SC, et al. (1987) Less food, less hunger: reports of appetite and symptoms in a controlled study of a protein-sparing modified fast. Int J Obes 11, 239-249.

18. Jequier E, Acheson K \& Schutz Y (1987) Assessment of energy expenditure and fuel utilization in man. Annu Rev Nutr 7, 187-208.

19. Gannon MC, Nuttall FQ, Westphal SA, et al. (1989) Effects of dose of ingested glucose on plasma metabolite and hormone responses in type II diabetic subjects. Diabetes Care 12, $544-552$.

20. Hill JO (2006) Understanding and addressing the epidemic of obesity: an energy balance perspective. Endocr Rev 27, $750-761$.

21. Butte NF \& Ellis KJ (2003) Comment on 'Obesity and the environment: where do we go from here?' author reply. Science 301, 598.

22. Swinburn BA, Jolley D, Kremer PJ, et al. (2006) Estimating the effects of energy imbalance on changes in body weight in children. Am J Clin Nutr 83, 859-863.

23. Weinsier RL, Bracco D \& Schutz Y (1993) Predicted effects of small decreases in energy expenditure on weight gain in adult women. Int J Obes Relat Metab Disord 17, 693-700.

24. Ravussin E (1995) Obesity in Britain. Rising trend may be due to 'pathoenvironment'. BMJ 311, 1569.

25. Seagle HM, Bessesen DH \& Hill JO (1998) Effects of sibutramine on resting metabolic rate and weight loss in overweight women. Obes Res 6, 115-121.

26. Hansen DL, Toubro S, Stock MJ, et al. (1998) Thermogenic effects of sibutramine in humans. Am J Clin Nutr 68, $1180-1186$

27. Yoshioka M, Doucet E, Drapeau V, et al. (2001) Combined effects of red pepper and caffeine consumption on $24 \mathrm{~h}$ energy balance in subjects given free access to foods. $\mathrm{Br} J$ Nutr $\mathbf{8 5}$, 203-211.

28. Yoshioka M, St-Pierre S, Drapeau V, et al. (1999) Effects of red pepper on appetite and energy intake. Br J Nutr 82, 115-123.

29. Reinbach HC, Smeets A, Martinussen T, et al. (2009) Effects of capsaicin, green tea and $\mathrm{CH}-19$ sweet pepper on appetite and energy intake in humans in negative and positive energy balance. Clin Nutr 28, 260-265. 